This item was submitted to Loughborough's Research Repository by the author.

Items in Figshare are protected by copyright, with all rights reserved, unless otherwise indicated.

\title{
Dynamic node lifetime estimation for wireless sensor networks
}

PLEASE CITE THE PUBLISHED VERSION

http://dx.doi.org/10.1109/JSEN.2013.2295303

PUBLISHER

(c) IEEE

VERSION

AM (Accepted Manuscript)

PUBLISHER STATEMENT

This work is made available according to the conditions of the Creative Commons Attribution-NonCommercialNoDerivatives 4.0 International (CC BY-NC-ND 4.0) licence. Full details of this licence are available at: https://creativecommons.org/licenses/by-nc-nd/4.0/

\section{LICENCE}

CC BY-NC-ND 4.0

\section{REPOSITORY RECORD}

Rukpakavong, Wilawan, Lin Guan, and lain Phillips. 2013. "Dynamic Node Lifetime Estimation for Wireless Sensor Networks". Loughborough University. https://hdl.handle.net/2134/23948. 


\title{
Dynamic Node Lifetime Estimation (DNLE) for Wireless Sensor Networks
}

\author{
Wilawan Rukpakavong, Lin Guan, and Iain Phillips
}

\begin{abstract}
Wireless Sensor Networks (WSNs) consist of a large number of nodes each with limited battery power. As networks of these nodes are usually deployed unattended, network lifetime becomes an important concern. This paper proposes a novel, feasible, dynamic approach for node lifetime estimation that works for both static and dynamic loads. It covers several factors that have an impact on node lifetime, including battery type, model, brand, self-discharge, discharge rate, age and temperature. The feasibility of the proposed scheme is evaluated by using the real testbed experiments with two wireless sensor platforms: Mica2 and N740 NanoSensor, two operating systems: TinyOS and Contiki, and different brands of alkaline and NickelMetal-Hydride (NiMH) batteries. The deviation of the proposed estimation is in the range of $-3.5 \%$ to $2.5 \%$. Three major contributions are presented in this paper: (1) the impact factors on node lifetime; (2) lifetime equations for any starting voltage, ageing, charge cycles and temperatures; (3) the dynamic node lifetime estimation technique (DNLE), which is proposed and implemented on real hardware and software platforms in WSNs.
\end{abstract}

Index Terms-Lifetime, battery capacity, current consumption, wireless sensor networks.

\section{INTRODUCTION}

W IRELESS sensor networks (WSNs) have two critical constraints: the first is that sensor nodes are often battery powered and thus have limited energy budgets; the second is that sensor nodes have a large number of nodes and usually deployed unattended, causing difficulty when replacing or recharging batteries across the entire network. Therefore, network lifetime (i.e. time while the network is usefully working) is an important issue. With accurate lifetime estimation of the sensor nodes, application designers can prevent service interruptions for critical applications. Moreover, many protocol layers, such as the MAC and routing layers, are able to make intelligent decisions that can help conserve energy and prolong lifetime.

Two important factors: battery capacity and current consumption are used for node lifetime estimation. In many studies [1]-[4], quoted capacity and calculations based on data sheets are usually used for battery capacity and measurements made for current consumption estimation. Furthermore, a fixed temperature is normally assumed (e.g., $25^{\circ} \mathrm{C}$ ). This means

Manuscript received September 23, 2013; revised November 07, 2013; accepted December 1, 2013; Date of publiction mmmm dd, 2014; date of current version $\mathrm{mmmm}$ dd, 2014. The associate editor coordinating the review of this paper and approving it for publication was Prof. Kiseon Kim.

W. Rukpapavong, L. Guan and I. Phillips are with the Department of Computer Science, Loughborough University, Leics, LE11 3TU, UK. e-mail: (W.Rukpakavong@lboro.ac.uk; L.Guan@lboro.ac.uk; I.W.Phillips@lboro.ac.uk). that running a static load program multiple times always consumes the same energy. However, in reality, programs will have different energy requirements resulting in different lifetimes [5]. Furthermore, the non-linear behaviour of the batteries needs to be taken into account. The challenge is to find an accurate lifetime estimation technique that covers temperature, battery age and self-discharge as well as other impact factors on node lifetime.

This paper proposes Dynamic Node Lifetime Estimation (DNLE), an approach that includes an investigation of the impact factors on node lifetime. DNLE has been implemented on real hardware: Mica2 [6] and N740 NanoSensor [7], and software platforms: TinyOS [8] and Contiki [9], [10]. Two common types of AA-size batteries: alkaline and NiMH have been investigated. This paper is organised as follows. Section II discusses the existing lifetime estimation algorithms. The impact factors on lifetime are examined in Section III. Section IV explains the design and implementation of the proposed method: DNLE. In Section V, an evaluation of DNLE is presented. Finally, Section VI is the conclusions and future work.

\section{Existing Lifetime Estimation Models}

The lifetime $(L t)$ of a sensor node can be considered to depend on two factors, the capacity of the battery $(C)$ and current consumption needed by that node $(I)$, which is expressed as [11]:

$$
L t=\frac{C}{I^{k}}
$$

where $k$ is the peukert constant, which depends on battery type [11]-[14]. It is therefore necessary to estimate both battery capacity and current consumption as well as have a knowledge of the battery type to determine an estimate of node lifetime.

\section{A. Battery Capacity Estimation}

There are several methods for determining the State of Charge (SoC) of the battery. This paper focuses the methods of electrochemical, voltage measurement, load testing and the electromotive force, which can be applied for alkaline and NiMH battery capacity estimation.

1) Electrochemical method: Since chemical energy in battery cells is converted into electrical energy through an electrochemical reaction, many studies [15], [16] propose electrochemical models based on the chemical processes that take place in the battery. These models describe the battery processes in great detail. However, they are very complex 
and require highly detailed knowledge of the electrochemical process, which makes them difficult to configure and deploy. An easy and accurate way is provided by measuring the specific gravity of the electrolyte in the battery using a hydrometer [11]. The specific gravity varies according to SoC level. When the SoC level decreases, the density of the electrolyte becomes lighter and the specific gravity becomes lower. An example of the relationship between the specific gravity and SoC is shown in Table I [11].

TABLE I

THE RELATIONSHIP BETWEEN THE SPECIFIC GRAVITY AND SOC [11]

\begin{tabular}{rr}
\hline Specific Gravity & SoC $(\%)$ \\
\hline 1.265 & 100 \\
1.239 & 75 \\
1.200 & 50 \\
1.170 & 25 \\
$<1.110$ & 0 \\
\hline
\end{tabular}

2) Voltage Measurement: Voltage measurement is a popular method for estimating current capacity, especially for mobile phone applications. For example, Heyer [17], [18] introduced a single-meter device for indicating the battery capacity on the basis of the measured battery voltage. This technique requires a look-up table in which fixed voltage values are stored and used in order to indicate SoC. For example, table II provides the relationship between voltage and $\mathrm{SoC}$ for Energizer $\mathrm{NiMH}$ battery [13].

TABLE II

THE RELATIONSHIP BETWEEN OUTPUT VOLTAGE AND SOC [13]

\begin{tabular}{rr}
\hline Voltage (V) & SoC $(\%)$ \\
\hline 1.45 & 100 \\
1.34 & 90 \\
1.30 & 80 \\
1.28 & $50-70$ \\
1.27 & 40 \\
1.25 & 30 \\
1.22 & 20 \\
1.14 & 10 \\
$<1$ & 0 \\
\hline
\end{tabular}

3) The ElectroMotive Force (EMF): The EMF is the internal driving force of a battery, providing energy to a load. Many studies [11], [19] found that there is a good linear relationship between the EMF and the $\mathrm{SoC}$ and this relationship does not change during cycling of the battery. To estimate SoC based on the EMF, a piecewise linear function is required. The intervals in voltage and the corresponding $\mathrm{SoC}$ are presented in Table III [11]:

$$
S o C=S o C_{\text {low }}+\frac{V_{m}-V_{\text {low }}}{V_{\text {high }}-V_{\text {low }}}\left(S o C_{\text {high }}-S o C_{\text {low }}\right)
$$

where $V_{m}$ is the measured battery voltage value, $V_{\text {low }}$ and $V_{\text {high }}$ are the specific values from the EMF curve for the voltages corresponding to the $S o C_{l o w}$ and $S o C_{h i g h}$, e.g., in Table III, $V_{\text {low }}=4.08$ and $V_{\text {high }}=4.24$ corresponding to $S o C_{l o w}=85$ and $S o C_{\text {high }}=100$, respectively. Therefore, the capacity of battery at $4.10 \mathrm{~V}$ is $\approx 87 \%$ of maximum.
TABLE III

THE INTERVALS IN VOLTAGE AND THE CORRESPONDING SOC FOR SONY US18500G3 LI-ION BATTERY [11]

\begin{tabular}{rrr}
\hline Interval number & Interval Voltage(V) & SoC $(\%)$ \\
\hline 1 & $4.08-4.24$ & $85.0-100$ \\
2 & $4.06-4.08$ & $81.7-85.0$ \\
3 & $4.02-4.06$ & $76.7-81.7$ \\
4 & $3.98-4.02$ & $73.4-76.7$ \\
5 & $3.88-3.98$ & $58.4-73.4$ \\
6 & $3.80-3.88$ & $22.0-58.4$ \\
7 & $3.68-3.80$ & $8.7-22.0$ \\
8 & $3.54-3.68$ & $5.4-8.7$ \\
9 & $3.32-3.54$ & $2.1-5.4$ \\
10 & $3.00-3.32$ & $0.5-2.1$ \\
11 & $2.50-3.00$ & $0.0-0.5$ \\
\hline
\end{tabular}

4) Load Testing: Battery capacity drops due to many factors, such as ageing and life cycle. Battery capacity testing by a load tester serves to determine the actual capacity of the battery. The load is usually designed to represent the expected conditions in which the battery may be used. With a battery load tester, a specific discharge current is applied to the battery while measuring the voltage drop. This is the most accurate and reliable battery testing technique [17]. Many battery load tester products support both alkaline and NiMH batteries, such as the ZTS MBT-MIL Multi-Battery Tester [20] and Ansmann Energy Check LCD Battery Tester [21]. However, these products automatically initiate a timed pulse load test on the battery upon detection in a terminal. This load test cannot be modified. In addition, these testers do not provide information related to temperature. The Computerised Battery Analyser-III (CBA-III) [22], a product from the West Mountain Radio, is a computer calibrated for high accuracy which uses an on-board microcontroller. A pulse width modulation system is used for controlling a pair of power MOS FET transistors using both electronic and software current regulation. The CBA-III allows for defining the load test from $0.1 \mathrm{~A}$ to $40 \mathrm{~A}$. Moreover, it provides information about the total amount of energy stored in a battery (capacity in amp-hours) and graphically displays and charts voltage versus amp-hours. Furthermore, a CBA-III supports the temperature measurement of a battery under test using the external temperature probe. In addition, a computer can connect to CBA-III via the USB interface onboard microcontroller for collecting the data.

5) Temperature Effect: Based on the famous Arrhenius equation, Sheridan et al. [23] proposed the ratio of capacity at two different temperatures in Kelvin $\left(T_{1}, T_{2}\right)$ as:

$$
\frac{C\left(T_{2}\right)}{C\left(T_{1}\right)}=\exp \left(A \cdot \frac{\left(T_{2}-T_{1}\right)}{T_{2} \cdot T_{1}}\right)
$$

where $A$ is a constant value obtained by dividing the activation energy (in $\mathrm{J} \mathrm{mol}^{-1}$ ) with the gas constant (in $\mathrm{J} \mathrm{mol}^{-1} \mathrm{~K}^{-1}$ ) of the battery. The relationship between battery capacity and lifetime was studied experimentally by Nguyen et al. [2] for different alkaline battery brands. The effect of temperature on NiMH battery capacity with different commercial AA-size NiMH batteries was explored by Pierozynski [24]. His work reported that the battery capacity is almost equal $96 \%$ at room temperature and it is dropped to $74 \%$ at $-20^{\circ} \mathrm{C}$ and $58 \%$ at 
$-30{ }^{\circ} \mathrm{C}$. The model proposed by Park et al. [25] covered the remaining capacity and the effect of temperature on battery capacity. From their experiment with rising temperature of $20^{\circ} \mathrm{C}$ to $60^{\circ} \mathrm{C}$, it was observed that the battery capacity increases around $0.5 \%$ of SoC when temperature increases by $1{ }^{\circ} \mathrm{C}$. With decreasing temperature from $20^{\circ} \mathrm{C}$ to $-10^{\circ} \mathrm{C}$, the battery capacity decreases $1.7 \%$ of SoC when temperature decreases $1^{\circ} \mathrm{C}$.

\section{B. Current Consumption Estimation}

There are several methods for determining the current consumption of sensor nodes. The existing mechanisms are hardware-based, software-based and include temperature effect supply voltage changes.

1) Hardware-based Mechanism: To estimate node current consumption, many current consumption models [26], [27] tried to design the special circuits for finding the average leakage current consumption; however, detailed knowledge of electrical circuits is required. Oscilloscopes or ammeters are commercially available for measuring the current draw from the circuit of sensor nodes with accurate results. Since the unique characteristics of sensor network applications make it difficult to measure the power and current consumption of each sensor node, Jiang et al. [28] developed hardware-based integrated circuits attached to sensor node boards for measuring the current consumption. This mechanism can capture phenomena such as per-node fluctuations.

2) Software-based Mechanism: Dunkels et al. [1] proposed a formula to calculate the energy consumption $(E)$.

$$
\frac{E}{V}=I_{a} t_{a}+I_{l} t_{l}+I_{t} t_{t}+I_{r} t_{r}+\sum I_{c} t_{c}
$$

where $V$ is the supply voltage, $I_{a}$ and $t_{a}$ are the current draw of the MCU (Microprocessor Control Unit) and time when the MCU has been running in active mode; $I_{l}$ and $t_{l}$ are the current draw and time of the MCU in low power or sleep mode; $I_{t}$ and $t_{t}$ are the current draw and the time of the communication device in transmit mode; $I_{r}$ and $t_{r}$ are the current draw and time of the communication device in receive mode; $I_{c}$ and $t_{c}$ are the current draw and time of other components such as sensors and LEDs. Then, the node current consumption $(I)$ rate is equal to $\frac{E}{V \cdot t}$ where $t$ is the time period. In this model, all current draw, supply voltage and temperature are assumed as fixed values (e.g., $3 \mathrm{~V}$ and $25^{\circ} \mathrm{C}$ as defined in the data sheet).

3) Temperature and Supply Voltage Effect: The current consumption of electronic circuit is affected by both temperature and supply voltage [2]. As temperature increases, current draw is increased. Liao et al. [29] proposed a leakage current model with temperature as:

$$
I(T)=I_{s} \cdot \exp \left(\frac{-\alpha}{T-\beta}\right)
$$

where $T$ is the temperature in Kelvin, $I_{s}$ is a constant current value, $\alpha$ and $\beta$ are the empirical constants which are decided by the circuit designs. Later, supply voltage is considered for leakage calculation as [26]:

$$
I\left(T, V_{d d}\right)=I_{s}\left(T_{0}, V_{0}\right) \cdot T^{2} \cdot \exp \left(\frac{\alpha \cdot V_{d d}+\beta}{T}\right)
$$

where $T$ is the temperature in Kelvin, $V_{d d}$ is the supply voltage, $I_{s}$ is a constant current at the reference temperature $T_{0}$ and supply voltage $V_{0}, \alpha$ and $\beta$ are the empirical constants which are decided by the circuit designs. It is assumed that the constant current $\left(I_{s}\right)$ is already known.

\section{Lifetime Estimation}

The review of some lifetime estimation techniques for real world WSNs is presented as follows:

1) Based on Voltage Drop Rate: Hao et al. [30] proposed a technique for lifetime estimation as:

$$
L t=\frac{V_{\text {init }}-V_{\text {cut }}}{V_{\text {rate }}}
$$

where $V_{\text {init }}$ is the initial voltage of battery, $V_{\text {cut }}$ is the cut-off voltage and $V_{\text {rate }}$ is the voltage drop rate. In their experiments, it is observed that the average voltage drop rates are $16.5 \mathrm{mV} /$ day for Mica2 and $21.5 \mathrm{mV} /$ day for MicaZ. With an initial voltage level of $3.2 \mathrm{~V}$ and the cut-off voltage of $2.2 \mathrm{~V}$, the estimated lifetime are $60.6 \mathrm{~d}$ for a Mica 2 and $46.5 \mathrm{~d}$ for a MicaZ.

2) Based on Quoted Capacity and Current Consumption: Selvig [31] presented a method to estimate the lifetime for sensor nodes based on CC2430 [32] as:

$$
L t=\frac{C}{\bar{I}}
$$

where $C$ is the battery capacity in $\mathrm{mAh}$ and $\bar{I}$ is the average current consumption. In this experiment, the battery capacity is assumed to be the quoted capacity from vendor and the average current consumption is measured by an oscilloscope. Since $\mathrm{I}=\frac{E}{V \cdot t}$, the software-based technique can be applied for finding the average current consumption by using (4).

3) Based on Quoted Capacity and Energy Consumption: Landsiedel and Wehrle [33], proposed an energy monitoring model, called AEON, for a sensor node as:

$$
E_{\text {rem }}=E_{\text {current }}-E
$$

where $E_{\text {current }}$ is the current battery capacity in $\mathrm{J}, E_{\text {rem }}$ is the remaining battery capacity in $\mathbf{J}$ and $E$ is the energy consumption which can be obtained by using (4). The initial value of $E_{\text {current }}$ is the initial capacity of battery in $\mathrm{J}$. The battery capacity is also assumed to be the quoted capacity from vendor. For example, a pair of alkaline batteries with $2500 \mathrm{mAh}$ of quoted capacity has $27000 \mathrm{~J}$ of the initial capacity. The lifetime of a node ends if $E_{r e m}$ of that node is empty. This model is implemented on top of AVRORA [34], a highly scalable sensor node simulator.

\section{Summary and Discussion}

Many SoC estimation techniques have been explored. Electrochemical methods require highly specific chemical knowledge which makes it difficult for real hardware implementation. Measuring the specific gravity is the uncomplicated 
way, but it is difficult to apply to sealed batteries [17], [35]. Voltage measurement is an easy and popular method. However, this measurement technique is not always an accurate indicator [17], [35]. Moreover, it is impossible to take into account every point of voltage in order to provide an accurate SoC indication system. The EMF method is more accurately implementable for many battery types. However, other factors, such as temperature and ageing, must be considered. Load testing is an accurate and reliable battery capacity estimation technique but the load test equipment is required. The temperature effect proposed by Sheridan et al. is a generic model which can be applied for many battery types but it is difficult to find detailed information from a vendor's specifications, such as the activation energy and gas of the battery. The model proposed by Park et al. covered the remaining capacity and the effect of temperature on battery capacity. However, they assumed the battery began with full capacity voltage, which might not apply for NiMH batteries because this battery type has a relatively high self-discharge rate on the first day after full charging.

Several mechanisms are used for finding the current draw of sensor nodes. Although a hardware-based mechanism can provide accurate results, it is of significantly high cost and complexity for large scale usage. Moreover, it is difficult to add to the existing hardware. In contrast, a software-based mechanism is easy to add to the existing system without additional per-unit cost. However, fixed voltage and current draw values are assumed for current consumption calculation using a software-based technique, which may not be accurate in realworld deployments as the current draw is usually dynamic, based on temperature and supply voltage. Temperature and supply-voltage-effect formulae focus only on the effects of the leakage current draw. They do not provide methods for finding the constant current draw.

A lifetime estimation model based on the voltage drop is suitable for a static load application. However, it is difficult to be applied in the real deployment since the load of each sensor is normally dynamic, which leads to dynamic voltage drop. Moreover, this technique is not always an accurate indicator [17], [35]. The other two methods are widely used by many studies. However, thery are based on quoted capacity and do not take other impact factors on lifetime, such as temperature and consumption rate, into account.

As a result of accurate node lifetime estimation, the challenge is to propose a new generic technique for finding the battery capacity which covers temperature, ageing and selfdischarging as well as other impact factors. Moreover, the software-based technique for finding the current consumption should be extended to cover the effect of temperature.

\section{The ImPACt FACtors on LifETIME}

Here we analyse the many factors causing the different lifetime periods, such as battery types, models, brands, selfdischarge, discharge rate, ageing, charge cycles and temperature.

\section{A. Battery Types, Brands and Models}

Table IV [12]-[14] shows the quoted capacity of two AAsize battery types: alkaline and $\mathrm{NiMH}$, from several brands and models.

TABLE IV

QUOTED CAPACITY FOR $100 \mathrm{~mA}$ DISCHARGE TO 0.9 V CUT-OFF AT ROOM TEMPERATURE

\begin{tabular}{lllr}
\hline Brands & Types & Models & $\begin{array}{r}\text { Quoted Capacity } \\
(\mathrm{mA} \mathrm{h})\end{array}$ \\
\hline A & Alkaline(AA-LR6) & A-Alkaline & 2750 \\
B & Alkaline(AA-LR6) & B-Alkaline & 2750 \\
C & Alkaline(AA-LR6) & C-Alkaline & 2750 \\
B & NiMH(AA-HR6) & B-NiMH1300 & 1430 \\
B & NiMH(AA-HR6) & B-NiMH2000 & 2200 \\
D & NiMH(AA-HR6) & D-NiMH2100 & 2310 \\
D & NiMH(AA-HR6) & D-NiMH2500 & 2750 \\
\hline
\end{tabular}

Based on the vendor data sheet, an AA-LR6 alkaline battery capacity for discharging at $100 \mathrm{~mA}$ to $0.9 \mathrm{~V}$ cut-off is around $2750 \mathrm{~mA} \mathrm{~h}$ [13], [14], while NiMH battery capacity is around $110 \%$ of the battery models, e.g., D-NiMH2100 model has $2310 \mathrm{mAh}$ of quoted capacity. However, only $90 \%$ from quoted capacity can be used for discharging to a cut-off voltage of $1 \mathrm{~V}$ for alkaline batteries, while $93 \%$ can be used for NiMH batteries [12]-[14]. From (1), lifetime can be easily estimated by dividing that battery capacity with the current load and assuming $k=1$. A constant $100 \mathrm{~mA}$ load generated by the CBA-III load tester is used for testing a pair of AA batteries at room temperature $\left(22^{\circ} \mathrm{C}\right)$. For NiMH batteries, they are charged by $500 \mathrm{~mA}$ charger and they are tested after being fully charged. The tested batteries are discharged until their terminal voltages reach the cut-off voltage at $2.0 \mathrm{~V}$ (of 2 cells). Table $\mathrm{V}$ shows the real measurement and estimation of lifetime. It is obvious that the battery model with high capacity has longer lifetime than the model with low capacity. With the same model of alkaline batteries, lifetime values of different brands have a little difference $( \pm 16 \mathrm{~min})$. The differences between estimated lifetime based on vendor data sheet and real measurement lifetime are around 7 to $15 \%$. These differences may be caused by other factors, such as selfdischarging, ageing and charge cycles which will be described in the following subsection.

TABLE V

MeAsuRed AND Estimated Lifetime of $100 \mathrm{~mA}$ Discharge to $2.0 \mathrm{~V}$ Cut-off at RoOM TEMPERATURE

\begin{tabular}{lrrr}
\hline Batteries & \multicolumn{2}{c}{$L t(\mathrm{~min})$} & Deviation \\
\cline { 2 - 3 } & Measured & Estimated & $(\%)$ \\
\hline A-Alkaline & 1384 & 1485 & 7.3 \\
B-Alkaline & 1370 & 1485 & 8.4 \\
C-Alkaline & 1368 & 1485 & 8.6 \\
B-NiMH1300 & 694 & 796 & 14.8 \\
B-NiMH2000 & 1144 & 1224 & 7.3 \\
D-NiMH2100 & 1115 & 1285 & 11.5 \\
D-NiMH2500 & 1410 & 1530 & 8.8 \\
\hline
\end{tabular}




\section{B. Self-discharge}

Since alkaline batteries will lose approximately $2 \%$ of their capacity per year when stored at $20^{\circ} \mathrm{C}$ due to the selfdischarging process [13], [14], there is no significant effect on capacity for several months for this type of battery. This means that the starting voltage of alkaline batteries can be assumed to be $1.5 \mathrm{~V}$ for each cell. In contrast, NiMH batteries have significantly high self-discharge of $20 \%$ on the first day and $1-4 \%$ per subsequent day. With self-discharging, they lose capacity and their voltages also drop. To study the relationship between starting terminal voltage $(V t)$ and lifetime, a CBA-III load tester with static $100 \mathrm{~mA}$ load testing runs with a pair of AA NiMH batteries from two brands, B-NiMH2000 and DNiMH2500, on two different starting $V t$ at room temperature $\left(22^{\circ} \mathrm{C}\right)$. Lifetime periods from the starting $V t$ to the minimum $V t$ (cut-off at $2.0 \mathrm{~V}$ ) are shown in Table VI.

TABLE VI

LiFETIME OF $100 \mathrm{~mA}$ LOAD WITH TwO AA NiMH BATTERIES

\begin{tabular}{lrr}
\hline Battery & $\begin{array}{r}\text { Starting } V t \\
(\mathrm{~V})\end{array}$ & $\begin{array}{r}\text { Measured } L t \\
(\mathrm{~min})\end{array}$ \\
\hline B-NiMH2000 & 2.81 & 1111 \\
& 2.88 & 1144 \\
D-NiMH2500 & 2.71 & 1197 \\
& 2.85 & 1264 \\
\hline
\end{tabular}

From this experiment, it is obvious that high starting $V t$ gives more lifetime period than low starting $V t$. Higher starting $V t$ means the higher battery energy which results longer lifetime. The proposed lifetime equation for any starting $V t$ is:

$$
L t(V t)=\left(-\tau \cdot \ln \left(\frac{V t_{r}}{V t}\right)\right)+L t\left(V t_{r}\right)
$$

where $\tau$ is the time constant representing capacity affected by self-discharging and $L t\left(V t_{r}\right)$ is the lifetime of the reference voltage $\left(V t_{r}\right)$. The time constant $\tau$ can be obtained by the following equation [11].

$$
\tau=\frac{t}{\ln \left(\frac{V t_{r 1}}{V t_{r 2}}\right)}
$$

where $t$ is the different time period between starting at $V t_{r 1}$ and $V t_{r 2}$ which is $L t\left(V t_{r 1}\right)-L t\left(V t_{r 2}\right)$. From Table VI, $t$ of B-NiMH2000 is $-33 \mathrm{~min}$, while $t$ of D-NiMH2500 is $-67 \mathrm{~min} . V t_{r 1}$ and $V t_{r 2}$ of $\mathrm{B}-\mathrm{NiMH} 2000$ are $2.81 \mathrm{~V}$ and $2.88 \mathrm{~V}$, while they are 2.71 and $2.85 \mathrm{~V}$ for D-NiMH2500. Therefore, $\tau, V t_{r}$ and $L t\left(V t_{r}\right)$ for B-NiMH2000 are 1341, 2.81, and 1111, while they are 1330, 2.71 and 1197 for DNiMH2500. These values are then used for calculating lifetime (in minutes) with any $V t$ between $V t_{r 1}$ and $V t_{r 2}$ based on (10). Measured and estimated lifetime of B-NiMH2000 and DNiMH2500 batteries with different starting voltages are shown in Table VII and VIII. The different starting voltages are caused by the self-discharging periods after full charging $(1 \mathrm{~h}$, $2 \mathrm{~h}, 3 \mathrm{~h}, 4 \mathrm{~h}$ and $5 \mathrm{~h}$ ).
TABLE VII

MEASURED AND EsTIMATEd LIFETIME FOR DifFERENT STARTING VOLTAGE OF B-NIMH2000 BATTERIES

\begin{tabular}{lrrrr}
\hline Voltage & Self-discharge & \multicolumn{2}{c}{$L t(\mathrm{~min})$} & Deviation \\
\cline { 3 - 4 }$(\mathrm{V})$ & time $(\mathrm{h})$ & Measured & Estimated & $(\%)$ \\
\hline 2.86 & 1 & 1138 & 1134 & -0.3 \\
2.85 & 2 & 1133 & 1130 & -0.3 \\
2.84 & 3 & 1127 & 1125 & -0.2 \\
2.84 & 4 & 1121 & 1125 & 0.4 \\
2.83 & 5 & 1117 & 1121 & 0.3 \\
\hline
\end{tabular}

TABLE VIII

MEASURED AND ESTIMATED LIFETIME FOR DIFFERENT STARTING VOLTAGE OF D-NIMH2500 BATTERIES

\begin{tabular}{lrrrr}
\hline Voltage & Self-discharge & \multicolumn{2}{c}{$L t(\mathrm{~min})$} & Deviation \\
\cline { 3 - 4 }$(\mathrm{V})$ & time (h) & Measured & Estimated & $(\%)$ \\
\hline 2.79 & 1 & 1250 & 1236 & -1.1 \\
2.78 & 2 & 1242 & 1231 & -0.9 \\
2.77 & 3 & 1235 & 1226 & -0.7 \\
2.76 & 4 & 1225 & 1221 & -0.3 \\
2.76 & 5 & 1223 & 1221 & -0.1 \\
\hline
\end{tabular}

\section{Discharge Rate}

The capacity of the battery varies with the rate of discharge. From the vendor data sheet with the discharge rate of $25 \mathrm{~mA}$ to $100 \mathrm{~mA}$ [13], [14], the capacity of the battery increases when the discharge rate decreases for alkaline batteries, while it decreases when the discharge rate decreases for NiMH batteries. If $C$ in (1) is the capacity of batteries when they are discharged at $100 \mathrm{~mA}$, peukert constant $(k)$ values are 0.96 and 1.004 for alkaline AA-LR6 and NiMH batteries, respectively [13], [14]. These $k$ constants are for a discharge rate of less than $100 \mathrm{~mA}$. For example, if lifetime for a $100 \mathrm{~mA}$ discharge rate for alkaline batteries is $25 \mathrm{~h}$ ( $2500 \mathrm{~mA} \mathrm{~h}$ capacity), the lifetime for a $25 \mathrm{~mA}$ discharge rate will be $114 \mathrm{~h}$ (calculated from $\left.\frac{2500}{25^{0.96}}\right)$; and if a lifetime for a $100 \mathrm{~mA}$ discharge rate for $\mathrm{NiMH}$ batteries is $27.5 \mathrm{~h}$ ( $2750 \mathrm{~mA} \mathrm{~h}$ capacity), lifetime for $25 \mathrm{~mA}$ of discharge rate will be $108.5 \mathrm{~h}$ (calculated from $\frac{2750}{25^{1.004}}$ ).

\section{Ageing}

The capacity of batteries will vary depending on their ageing. Normally, battery packages have a date code on them indicating the use by date that the batteries can be used with good capacity (70-80\% of quoted capacity) [11], [13]. Therefore, the ageing effect on lifetime is presented as:

$$
\operatorname{Lt}(a)=(1-\rho \cdot a) \cdot \operatorname{Lt}(\text { new })
$$

where $a$ is the age of the battery in years, $\rho$ is the ageing factor and $L t(n e w)$ is the lifetime of the new battery. For examples, the capacity of alkaline batteries will reduce $2 \%$ per year [13], [14] when stored at room temperature $\left(20^{\circ} \mathrm{C}\right)$. This means that the lifetime of the device will be reduced $2 \%(\rho=0.02)$ each year due to the age of the batteries. Therefore, the new AALR6 batteries will give 1350 min of lifetime for a device with $100 \mathrm{~mA}$ load, while they will give $1323 \mathrm{~min}$ of lifetime when storing these batteries for one year before using. For NiMH 
batteries, the capacity will drop 6\% $(\rho=0.06)$ per year due to their ageing when stored at room temperature [12], [13]. Therefore, the new D-NiMH2500 battery will give $1410 \mathrm{~min}$ after being fully charged, while they will give $1325 \mathrm{~min}$ after being fully charged if they have one year of age.

\section{E. Charge Cycles}

The charge cycles factor has an effect on rechargeable batteries by measuring how many times the batteries have been recharged. NiMH batteries can deliver $100 \%$ capacity for up to 300 charge cycles, while their capacity will reduce $0.1 \%$ for each charge cycle for more than 300 cycles [12], [13]. As a result, a decrease of lifetime can be described as:

$$
L t(c)= \begin{cases}L t(\text { new }) & \text { if } c \leq 300 \\ (1.3-0.001 c) \cdot \operatorname{Lt}(\text { new }) & \text { otherwise }\end{cases}
$$

where $c$ is the number of charge cycles and $\operatorname{Lt}($ new) is the lifetime of the new battery. For example, the new DNiMH2500 battery will give $1410 \mathrm{~min}$, while they will give 1269 min at 400 charge cycles $(c=400)$.

\section{F. Temperature}

Both battery capacity and current consumption are affected by temperature. As temperature increases, the current draw is increased and, consequently, shortens the lifetime of the device. However for alkaline and NiMH cells, high temperature can provide increased capacity of battery over the operating temperature range 0 to $40^{\circ} \mathrm{C}$. Therefore, it depends on the ratio between increased battery capacity and current draw, which may result in increased or decreased lifetime. Based on (3) and information contained in vendor data sheets [12]-[14], [23], the constant $A$ which depends on the activation energy and gas of the battery can be calculated as Table IX.

TABLE IX

CAPACITy of Different Temperatures and Constant Value for DIFFERENT BATTERIES

\begin{tabular}{lrrr}
\hline Batteries & $\begin{array}{r}\text { Capacity } \\
\left(\mathrm{mAh} @ 0{ }^{\circ} \mathrm{C}\right)\end{array}$ & $\begin{array}{r}\text { Capacity } \\
\left(\mathrm{mAh} @ 25^{\circ} \mathrm{C}\right)\end{array}$ & $A$ \\
\hline A-Alkaline & 900 & 1950 & 2518.73 \\
B-Alkaline & 857 & 1942 & 2665.53 \\
B-NiMH2000 & 1717 & 2113 & 677.19 \\
D-NiMH2500 & 2127 & 2667 & 737.11 \\
\hline
\end{tabular}

Based on (6), the leakage current draw at two different average temperatures in Kelvin $\left(T_{1}, T_{2}\right)$ can be defined as:

$$
\frac{I\left(T_{2}\right)}{I\left(T_{1}\right)}=\frac{T_{2}^{2}}{T_{1}^{2}} \cdot \exp \left(\frac{K \cdot\left(T_{1}-T_{2}\right)}{T_{1} \cdot T_{2}}\right)
$$

where $K$ is a constant depending on the circuit and $V_{d d}$. It is assumed that $V_{d d}$ is the same for these two different temperatures. The real experiments have been conducted for Mica2 and N740 Nanosensor with a simple static load program at two different temperatures. The $V_{d d}$ is static at $3.0 \mathrm{~V}$. Table $\mathrm{X}$ shows the measured current draw by an ammeter and calculated $K$ constant results.
TABLE $X$

CURRENT DRAW AT DIFFERENT TEMPERATURES AND $K$ VALUE FOR MiCA2 AND N740 MOTES

\begin{tabular}{lrrr}
\hline Sensor & $\begin{array}{r}\text { Current } \\
\left(\mathrm{mA} @ 55^{\circ} \mathrm{C}\right)\end{array}$ & $\begin{array}{r}\text { Current } \\
\left(\mathrm{mA} @ 255^{\circ} \mathrm{C}\right)\end{array}$ & $K$ \\
\hline Mica2 & 12 & 18 & -1105.43 \\
N740 & 47 & 66 & -831.94 \\
\hline
\end{tabular}

From (1), (3) and (14), node lifetime with full capacity at two different temperatures is derived as:

$$
\frac{L t\left(T_{2}\right)}{L t\left(T_{1}\right)}=\frac{T_{1}^{2}}{T_{2}^{2}} \cdot \exp \left(\sigma \cdot\left(\frac{T_{2}-T_{1}}{T_{2} \cdot T_{1}}\right)\right)
$$

where $\sigma$ is the $A+K$ values which can be obtained from Table IX and X and are presented in Table XI.

TABLE XI

Ratio Constant Value of DifFEREnt Batteries For Mica2 AND N740 MOTES

\begin{tabular}{llr}
\hline Sensor & Batteries & $\sigma$ \\
\hline Mica2 & A-Alkaline & 1413.30 \\
Mica2 & B-Alkaline & 1560.10 \\
Mica2 & B-NiMH2000 & -428.24 \\
Mica2 & D-NiMH2500 & -368.33 \\
N740 & A-Alkaline & 1686.80 \\
N740 & B-Alkaline & 1833.59 \\
N740 & B-NiMH2000 & -154.74 \\
N740 & D-NiMH2500 & -94.83 \\
\hline
\end{tabular}

The experiments are conducted to test the temperature effect on the lifetime of N740 mote with two NiMH batteries: BNiMH2000 and D-NiMH2500. A simple program runs on different temperatures. This program load as measured by an ammeter at $25^{\circ} \mathrm{C}$ is $67 \mathrm{~mA}$. From Table IX, capacity of B-NiMH2000 and D-NiMH2500 batteries at $25^{\circ} \mathrm{C}$ are 2113 and $2667 \mathrm{mAh}$. Therefore, node lifetime at $25^{\circ} \mathrm{C}$ will be $31.01 \mathrm{~h}\left(\frac{2113}{67^{1.004}}\right)$ and $39.14 \mathrm{~h}\left(\frac{2667}{67^{1.004}}\right)$ for B-NiMH2000 and D-NiMH2500, respectively. However, the experiments run at temperatures between 19 to $24^{\circ} \mathrm{C}$. The results of real lifetime and estimated lifetime based on (15) including deviation are presented in Table XII.

TABLE XII

LIFETIME WITH DIFFERENT NIMH BATTERIES AND TEMPERATURES FOR N740 MOTES

\begin{tabular}{lrrrr}
\hline Batteries & Temperature & \multicolumn{2}{c}{$L t(\mathrm{~min})$} & Deviation \\
\cline { 3 - 4 } & $\left({ }^{\circ} \mathrm{C}\right)$ & Measured & Estimated & $(\%)$ \\
\hline B-NiMH2000 & 20.0 & 1953 & 1941 & -0.61 \\
B-NiMH2000 & 21.0 & 1920 & 1924 & 0.21 \\
B-NiMH2000 & 24.0 & 1885 & 1875 & -0.53 \\
D-NiMH2500 & 19.5 & 2462 & 2451 & -0.45 \\
D-NiMH2500 & 20.0 & 2445 & 2441 & -0.16 \\
D-NiMH2500 & 22.0 & 2417 & 2403 & -0.58 \\
\hline
\end{tabular}

\section{DNLE DESIGN AND IMPLEMENTATION}

This research proposes formulae and processes for dynamic node lifetime estimation which covers many factors causing 
the different lifetime periods, such as battery type, model, brand, self-discharge, discharge rate, ageing and temperature. These formulae do not require detailed electrical and electrochemical knowledge. Moreover, some limitations, such as memory and arithmetic capabilities, have to be taken into account for real implementation on sensor nodes. DNLE is based on the following assumptions for both alkaline and NiMH batteries. First, batteries from the same pack have the same performance and behaviour. Second, storing temperature does not affect the capacity change since the batteries are always stored at room temperature. Third, for NiMH batteries, charging method does not affect the capacity change since the same charger is used in these experiments. Fourth, temperature during charging does not affect the capacity change since the batteries are always charged at room temperature. Last, batteries have suffered fewer than 300 charging cycles.

\section{A. DNLE Design}

The following steps are proposed for finding the lifetime of each node:

1) Step 1: Finding the real battery capacities:

a) Alkaline Batteries: It is sometimes difficult to determine the battery capacity reduction due to ageing since the manufacture date is not available. Moreover, some batteries may have lower capacity than quoted. It can be assumed that batteries sampled from the same manufactured batch can be representative of that batch. Each sample pair is tested by the load testing with static $100 \mathrm{~mA}$ load in order to find the real battery capacity with cut-off voltage equal to the minimum voltage of sensor motes. In these experiments, the cut-off voltage is $2.2 \mathrm{~V}$. After that, the real battery capacity (in $\mathrm{mAh}$ ) can be calculated by:

$$
C=L t \cdot 100
$$

where $L t$ is the lifetime of the batteries in hours. For example, if a pair of alkaline batteries gives $22.5 \mathrm{~h}$ of lifetime, the capacity value is $2250 \mathrm{~mA} \mathrm{~h}$. Instead of using quoted capacity, a sample average will be assigned as the capacity for batteries from this batch. The temperature $\left(T_{t}\right)$ when running load testing is recorded. If $T_{i}$ is the temperature when a node starts running, the initial capacity with temperature effect can be calculated by using (3) with $T_{2}$ as $T_{i}$ and $T_{1}$ as $T_{t}$. We refer to this value as $C\left(T_{i}\right)$.

b) NiMH Batteries: For NiMH batteries, each sample pair is tested after full charging in a similar way to the alkaline type. However, since NiMH batteries have significantly high self-discharge on the first day, each sample pair is retested again after letting it $24 \mathrm{~h}$ of self-discharge. With self-discharging, the starting voltage of batteries is different from being fully charged. The starting voltage of fully charged batteries is referred as $V t_{f}$ and the starting voltage of batteries with $24 \mathrm{~h}$ of self-discharge is referred as $V t_{24 h}$. The capacities of two different starting voltages are referred as $C_{f}$ for the capacity of fully charged batteries and $C_{24 h}$ for the capacity of $24 \mathrm{~h}$ of self-discharge batteries. Then, the battery capacity of any starting voltage $(V t)$ between $V t_{24 h}$ and $V t_{f}$ can be calculated as:

$$
C(V t)=\left(-\tau \cdot \ln \left(\frac{V t_{24 h}}{V t}\right)\right)+C\left(V t_{24 h}\right)
$$

where $\tau$ is the constant representing capacity affected by selfdischarging which can be obtained by:

$$
\tau=\frac{c}{\ln \left(\frac{V t_{24 h}}{V t_{f}}\right)}
$$

where $c$ is $C_{24 h}-C_{f}$. It is assumed that the temperature $\left(T_{t}\right)$ is the same when running load testing with fully charged and $24 \mathrm{~h}$ of self-discharge batteries. If $T_{i}$ is the temperature when a node starts running, the initial capacity with temperature effect can be calculated by using (3) with $T_{2}$ as $T_{i}$ and $T_{1}$ as $T_{t}$. We refer to this value as $C\left(V t, T_{i}\right)$.

2) Step 2: Finding the current consumption every period: Adapted from (4) proposed by Dunkels et al., the current consumption at a period can be expressed as:

$$
I=I_{a} t_{a}+I_{l} t_{l}+I_{t} t_{t}+I_{r} t_{r}+\sum I_{c} t_{c}
$$

where $I_{a}$ and $t_{a}$ are the current consumption of the MCU (Microprocessor Control Unit) and the time when the MCU has been running in active mode during a period; $I_{l}$ and $t_{l}$ are the current consumption and time of the MCU in low power or sleep mode during a period; $I_{t}$ and $t_{t}$ are the current consumption and the time of the radio transceiver in transmit mode during a period; $I_{r}$ and $t_{r}$ are the current consumption and time of the radio transceiver in receive mode during a period; $I_{c}$ and $t_{c}$ are the current consumption and time of other components such as sensors and LEDs during a period. The calculation as this equation is applied based on device data sheet with temperature at $25^{\circ} \mathrm{C}$. The current consumption has to be calculated every period. Thus, the average current consumption $(\bar{I})$ for $s$ periods can be computed by using the Simple Moving Average as:

$$
\bar{I}(s)=\gamma \cdot \bar{I}(s-1)+(1-\gamma) \cdot I(s)
$$

where $\gamma$ is the weighting value $=\frac{s-1}{s}, \bar{I}(s-1)$ is average current consumption of the previous period, and $I(s)$ is the current consumption at the period $s$. If $T$ is the temperature of the current period, the current consumption $I(s, T)$ and average current consumption $\bar{I}(s, T)$ can be calculated by using (14) with $T_{2}$ as $T$ and $T_{1}$ as $298.15\left(25^{\circ} \mathrm{C}\right.$ is $\left.298.15 \mathrm{~K}\right)$.

3) Step 3: Remaining lifetime estimation: The remaining capacity $\left(C_{r e m}\right)$ at period $s$ can be obtained by:

$$
C_{r e m}(s)=C_{r e m}(s-1)-I(s, T)^{k}
$$

where $k$ is the peukert constant, $C_{r e m}(s-1)$ is the remaining capacity before period $s$ and it is equal to the initial capacity for the first period. This means that if $s=1, C_{r e m}(s-1)$ $=C\left(T_{i}\right)$ for alkaline batteries and $C_{r e m}(s-1)=C\left(V t, T_{i}\right)$ for NiMH batteries. If $T$ is the temperature of the current period, the temperature effect on the capacity is calculated by using (3), with $T_{2}$ as $T$ and $T_{1}$ as the temperature of the previous period. We refer to this value as $C_{r e m}(s, T)$. Finally, 
the remaining lifetime at the current period and temperature $L t_{r e m}(\mathrm{~s}, \mathrm{~T})$ can be estimated as:

$$
\operatorname{Lt}_{r e m}(s, T)=\frac{C_{r e m}(s, T)}{\bar{I}(s, T)^{k}}
$$

\section{B. DNLE Implementation}

DNLE has been implemented on two real hardware platforms, Mica2 and N740 NanoSensor with operating systems TinyOS and Contiki respectively. It was assumed that sensor motes support battery voltage and temperature reading. The process is as follows:

1) Process 1: Preconfigured and Starting process: Two AA-LR6 alkaline models (A-Alkaline and B-Alkaline) and two NiMH models (B-NiMH2000 and D-NiMH2500) are the batteries used in the experiments. The capacities of these battery packs are evaluated by using the CBA-III load tester with static $100 \mathrm{~mA}$ current at $25^{\circ} \mathrm{C}$. Three pairs of batteries are tested for finding the average values of each battery model. These average capacities are then used as the preconfigured values for sensor nodes. All preconfigured values are given in Table IX, X and XIII. All nodes may automatically obtain these preconfigured values during the discovery process, but it is out of scope in this research. When a node starts, it reads the current temperature and battery starting voltage in order to calculate the initial battery capacity as described in Step1 of the DNLE design section.

TABLE XIII

Preconfigured CAPACITIES OF BATteries

\begin{tabular}{lr}
\hline Battery & $\begin{array}{r}\text { Capacity at } 25^{\circ} \mathrm{C} \\
(\mathrm{mA} \mathrm{h})\end{array}$ \\
\hline A-Alkaline & 1850 \\
B-Alkaline & 1800 \\
B-NiMH2000 & 1585 \\
D-NiMH2500 & 1814 \\
\hline
\end{tabular}

2) Process 2: Looping process: We focus on three components: MCU, radio transceiver and sensing device, for finding the current consumption at runtime. The current draw of these components is configured based on the device data sheet. The device driver of these components is modified: time stamps are recorded when the components are turned on, and time differences are computed when the components are turned off. These time differences (with the same unit of the period) are used for the current consumption calculation based on (19). One minute is used as the time period (Step2 of the DNLE design section). Since the battery capacity is hours unit, it needs to be converted to the same unit of the period (e.g., $2000 \mathrm{mAh}=120000 \mathrm{mAmin}$ for a period of 1 minute) . Temperature readings are repeated every minute for updating the current temperature in order to calculate the effect on the current consumption, average current consumption, remaining capacity and remaining lifetime as described in Step2 and Step3 of the DNLE design section.

\section{DNLE Evaluation}

This section evaluates the proposed technique on real testbed experiments with two different hardware platforms
(Mica2 based on CC1000 radio and the ATMega128L [36], [37], and N740 Nanosensor based on CC2431 [32], [38], a SoC combining the $\mathrm{CC} 2420$ radio with $8051 \mathrm{MCU}$ ) and four battery models: A-Alkaline, B-Alkaline, B-NiMH2000 and D-NiMH2500. The N740 platform is implemented using Contiki OS, while Mica2 platform is implemented using TinyOS. Two techniques: Selvig's method and the DNLE are investigated. Lifetime estimation is made every minute. For Selvig's method, battery capacity is obtained by using quoted capacity as in Table IV, while the current consumption is calculated using (19). In these experiments $80 \%$ of quoted capacity is used (as a cut-off voltage of $2.2 \mathrm{~V}$ ) for alkaline batteries and $91 \%$ for NiMH batteries [12]-[14]. Therefore, usable capacities are $2200 \mathrm{~mA}$ h for A-Alkaline, $2200 \mathrm{~mA} \mathrm{~h}$ for B-Alkaline, $2102 \mathrm{mAh}$ for B-NiMH2000 and $2502 \mathrm{~mA} \mathrm{~h}$ for D-NiMH2500. For DNLE, the processes are as described in the DNLE design and implementation section. In general, the current consumption of the sensor node is less than $100 \mathrm{~mA}$. Therefore, the peukert constant values are 0.96 and 1.004 for the alkaline and NiMH batteries, respectively.

These experiments consist of two nodes, the sender and the base station. The base station is placed in the normal room conditions, while the sender is placed in a controlled environment in order to operate under a static temperature $\left(10^{\circ} \mathrm{C}\right.$ and $\left.22^{\circ} \mathrm{C}\right)$ as in Fig. 1. Two scenarios: static and dynamic loads are applied in the experiments.

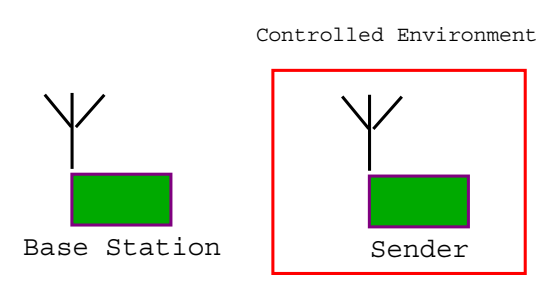

Fig. 1. Dynamic Node Lifetime Estimation Experiment

\section{A. Scenariol: Static Load}

For static load, the sender sends a fixed sized packet of $50 \mathrm{~B}$ to the base station every $3 \mathrm{~s}$. Two sensor motes (Node1 and Node2) are used. Node1 runs as the sender for the first 3 times, while Node2 is the sender for the other 3 times. Lifetime estimation is calculated only at the sender node. NiMH batteries are given random starting voltages by a random self-discharging period of $5 \mathrm{~min}$ to $600 \mathrm{~min}$. The average deviation results for two mote platforms with different battery models are shown in Table XIV. Since Selvig's method does not take some impact factors (such as charging rate, self-discharging and temperature) into account, the estimated values are much different from the measured ones around $19.1 \%$ to $60.3 \%$. On the other hand, they are in the range of $-3.5 \%$ to $2.4 \%$ for DNLE.

\section{B. Scenario2: Dynamic Load}

In a real deployment, a load of each sensor is normally dynamic, which may be caused by monitoring events or 
TABLE XIV

Average Deviation of Static Load Lifetime Estimation Testbed RESULTS FOR MICA2 AND N740 MOTES WITH DIFFERENT BATTERIES

\begin{tabular}{llrrr}
\hline Sensor & Battery & Temp. & \multicolumn{2}{c}{ Estimated $L t$ Deviation(\%) } \\
\cline { 4 - 5 } & & 22 & 22.4 & -1.0 \\
& & 10 & 38.9 & -1.4 \\
Mica2 & A-Alkaline & Selvig's Method & DNLE \\
Mica2 & A-Alkaline & 22 & 30.4 & -2.5 \\
Mica2 & B-Alkaline & 10 & 50.0 & -3.5 \\
Mica2 & B-Alkaline & 1.5 & 1.5 \\
Mica2 & B-NiMH2000 & 22 & 33.3 & 2.4 \\
Mica2 & B-NiMH2000 & 10 & 53.4 & -1.4 \\
Mica2 & D-NiMH2500 & 22 & 36.6 & 0.8 \\
Mica2 & D-NiMH2500 & 10 & 19.1 & 1.7 \\
N740 & A-Alkaline & 22 & 41.1 & 1.9 \\
N740 & A-Alkaline & 10 & 26.3 & -0.2 \\
N740 & B-Alkaline & 22 & 50.9 & -1.3 \\
N740 & B-Alkaline & 10 & 23.5 & 1.0 \\
N740 & B-NiMH2000 & 22 & 21.7 & 2.0 \\
N740 & B-NiMH2000 & 10 & 41.8 & 2.1 \\
N740 & D-NiMH2500 & 22 & 39.5 & 2.0 \\
N740 & D-NiMH2500 & 10 & & \\
\hline
\end{tabular}

the number of neighbour nodes. For dynamic load in this experiment, the sender sends a packet of a random size of $20 \mathrm{~B}$ to $50 \mathrm{~B}$ to the base station every $x$ seconds. The interval time value $(x)$ was changed randomly every $10 \mathrm{~min}$ to between $3 \mathrm{~s}$ and $6 \mathrm{~s}$. The testbed experiments run at temperatures of 10 and $22{ }^{\circ} \mathrm{C}$. Two sensor motes (Node1 and Node2) are used. Node1 runs as the sender for the first 3 times, while Node2 is the sender for the other 3 times. Lifetime estimation is calculated only at the sender node. For NiMH batteries, they have random starting voltages by a random self-discharging period between $5 \mathrm{~min}$ to $600 \mathrm{~min}$. The average deviation results for two mote platforms with different battery models are shown in Table XV. The deviation of Selvig's method is $18.7 \%$ to $57.5 \%$, while it is $-2.1 \%$ to $2.5 \%$ for DNLE.

TABLE XV

Average Deviation of Dynamic Lode LifETime Estimation Testbed Results For MiCA2 AND N740 Motes With DifFERENT BATTERIES

\begin{tabular}{llrrr}
\hline Sensor & Battery & Temp. & \multicolumn{2}{c}{ Estimated $L t$ Deviation(\%) } \\
\cline { 4 - 5 } & & 22 & 21.0 & -1.4 \\
& & 10 & 37.8 & -1.4 \\
& & 22 & 30.6 & -1.6 \\
Mica2 & A-Alkaline & 57.5 & 2.1 \\
Mica2 & A-Alkaline & 33.9 & 2.5 \\
Mica2 & B-Alkaline & 22 & 22.4 & -1.8 \\
Mica2 & B-Alkaline & 10 & 54.7 & -0.6 \\
Mica2 & B-NiMH2000 & 22 & 32.8 & -2.1 \\
Mica2 & B-NiMH2000 & 10 & 18.7 & 1.4 \\
Mica2 & D-NiMH2500 & 22 & 40.5 & 1.4 \\
Mica2 & D-NiMH2500 & 10 & 26.0 & -0.5 \\
N740 & A-Alkaline & 22 & 50.2 & -1.7 \\
N740 & A-Alkaline & 10 & 33.6 & 0.7 \\
N740 & B-Alkaline & 22 & 21.2 & 1.6 \\
N740 & B-Alkaline & 10 & 41.4 & 1.8 \\
N740 & B-NiMH2000 & 22 & 35.9 & 1.5 \\
N740 & B-NiMH2000 & 10 & & DNLE \\
N740 & D-NiMH2500 & 22 & \\
N740 & D-NiMH2500 & 10 & & \\
\hline
\end{tabular}

\section{CONCLUSions AND Future WORK}

In this paper, impact factors on node lifetime, such as battery brand, type, model, self-discharge, charging rate, bat- tery ageing, charge cycles, and temperature, are investigated and analysed. Lifetime equations for any starting voltage, ageing, charge cycles and temperatures are proposed to explain the effect of the impact factors. Moreover, a dynamic node lifetime estimation technique, called DNLE is proposed. The experiments have been conducted on real hardware and software platforms in WSNs with different battery models. Two scenarios, dynamic and static loads, are implemented to evaluate the deviation of DNLE comparing to Selvig's method. The estimated values of Selvig's method are much different from the measured ones (around $18 \%$ to $60 \%$ ), while they are close to the measured ones for DNLE $(-3.5 \%$ to $2.5 \%)$ due to taking some impact factors into account, such as charging rate, self-discharging and temperature. It can be concluded that node lifetime can be predicted more accurately using DNLE, which can be applied for both off-line and on-line lifetime estimation.

Future work will include battery recovery effects when nodes employ dynamic duty cycling. Furthermore, the higher than room temperature and the impact of humidity should be investigated. In addition, the network lifetime will be further benefited with the integration of DNLE into the network routing process.

\section{REFERENCES}

[1] A. Dunkels, F. Osterlind, N. Tsiftes, and Z. He, "Software-based on-line energy estimation for sensor nodes," in Proceedings of the 4th Workshop on Embedded Networked Sensors, 2007, pp. 28-32.

[2] H. A. Nguyen, A. Forster, D. Puccinelli, and S. Giordano, "Sensor node lifetime: An experimental study," in IEEE International Conference on Pervasive Computing and Communications Workshops, PERCOM Workshops, 2011, pp. 202-207.

[3] W. Rukpakavong, I. Phillips, and L. Guan, "Neighbour discovery for transmit power adjustment in IEEE 802.15.4 using RSSI," in New Technologies, Mobility and Security (NTMS), 2011 4th IFIP International Conference on, feb. 2011, pp. 1-4.

[4] W. Rukpakavong, I. Phillips, L. Guan, and G. Oikonomou, "RPL router discovery for supporting energy-efficient transmission in singlehop 6LoWPAN," in Communications (ICC), 2012 IEEE International Conference on, jun. 2012, pp. 5721-5725.

[5] W. Rukpakavong, I. Phillips, and L. Guan, "Lifetime estimation of sensor device with AA NiMH batteries," in IPCSIT vol. 55, International Conference on Information Communication and Management (ICICM), oct. 2012, pp. 98-102.

[6] Mica2 Wireless Measurement System. [Online]. Available: http://bullseye.xbow.com:81/Products/Product_pdf_files/Wireless_pdf/M ICA2_Datasheet.pdf

[7] S. Ltd. (2008) Sensinode Ltd. joins Texas Instruments low-power RF developer network, offers IPv6 wireless network solutions based on 6lowpan standard technology. [Online]. Available: http://embeddedcomputing.com/sensinode-based-6lowpan-standard-technology

[8] U. Berkeley. (2004) What is tinyos? [Online]. Available: http://www.tinyos.net

[9] A. Dunkels, B. Gronvall, and T. Voigt, "Contiki - a lightweight and flexible operating system for tiny networked sensors," in Proceedings of the 29th Annual IEEE International Conference on Local Computer Networks, ser. LCN '04. Washington, DC, USA: IEEE Computer Society, 2004, pp. 455-462.

[10] G. Oikonomou and I. Phillips, "Experiences from porting the Contiki operating system to a popular hardware platform," in Proceeding of 2011 International Conference on Distributed Computing in Sensor Systems and Workshops (DCOSS), Barcelona, Spain, Jun. 2011.

[11] H. Bergveld, W. Kruijt, and P. Notten, Battery Management Systems: Design by Modelling (Philips Research Book Series). Springer, 2002.

[12] GP Battery Datasheet. [Online]. Available: http://www.gpbatteries.com

[13] Energizer Battery Datasheet. [Online]. Available: http://www.energizer.com 
[14] Duracell Battery Datasheet. [Online]. Available: http://www.duracell.com

[15] Q. Zhang, Q. Guo, S. Liu, R. A. Dougal, and R. E. White, "Resistive companion modeling of batteries in a virtual test bed," Journal of Power Sources, vol. 141, no. 2, pp. 359-368, 2005.

[16] G. S. Nagarajan and J. V. Zee, "Characterization of the performance of commercial NiMH batteries," Journal of Power Sources, vol. 70, no. 2, pp. 173-180, 1998.

[17] V. P. Henk, H. J. Bergveld, D. Danilov, P. P. Regtien, and P. H. Notten, Battery Management Systems: Accurate State-of-Charge Indication for Battery-Powered Applications. Springer, 2008.

[18] B. Heyer, "One meter battery tester," US Patent 2,225,051, May 1938.

[19] W. Guoliang, L. Rengui, Z. Chunbo, and C. Chan, "State of charge estimation for NiMH battery based on electromotive force method," in Vehicle Power and Propulsion Conference, VPPC '08, sept. 2008, pp. $1-5$.

[20] Z. Inc. (2008) The ZTS MBT-MIL multi-battery tester (MBT-MIL). [Online]. Available: http://www.ztsinc.com/MBTMIL_OI.pdf

[21] Ansmann. Ansmann energy check LCD battery tester. [Online]. Available: http://www.farnell.com/datasheets/39714.pdf

[22] W. M. Radio. Computerized battery analyzer (CBA). [Online]. Available: http://www.westmountainradio.com/cba.php

[23] C. Sheridan, J. Petersen, and J. Rohwer, "On modifying the Arrhenius equation to compensate for temperature changes for reactions within biological systems," in Water SA, vol. 38, no. 1, jan. 2012.

[24] B. Pierozynski, "On the low temperature performance of Nickel-Metal Hydride (NiMH) batteries," International Journal of Electrochemical Science, vol. 6, pp. 860-866, 2011.

[25] C. Park, K. Lahiri, and A. Ranghunathan, "Battery discharge characteristics of wireless sensor nodes: An experimental analysis," in The 2nd Annual IEEE Communications Society Conference on Sensor and Ad Hoc Communications and Networks (SECONO5), CA, USA, 2005.

[26] W. Liao, L. He, and K. M. Lepak, "Temperature and supply voltage aware performance and power modeling at microarchitecture level," IEEE transaction on computer-aided design of integrated circuits and systems, vol. 24, no. 7, pp. 1042-1053, jul. 2005.

[27] N. H. E. Weste and K. Eshraghian, The Principles of CMOS VLSI Design. Reading, U.K: MA:Addison-Wesley, 1993

[28] X. Jiang, P. Dutta, D. Culler, , and I. Stoica, "Micro power meter for energy monitoring of wireless sensor networks at scale," in Proceedings of the 6th international conference on Information processing in sensor networks, IPSN 07, Massachusetts, USA, 2007, p. 186195.

[29] W. Liao, F. Li, and L. He, "Microarchitecture level power and thermal simulation considering temperature dependent leakage model," in Proceedings of the 2003 international symposium on Low power electronics and design, ser. ISLPED '03. New York, NY, USA: ACM, 2003, pp. $211-216$.

[30] S. Hao, M. C. Chan, B. Anand, and A. L. Ananda. Structure health monitoring at MRT construction sites using wireless sensor networks link measurement at Pasir Panjang station. [Online]. Available: http://www.cir.nus.edu.sg/mrt-proj-report.pdf

[31] B. Selvig, "Measuring power consumption with CC2430 \& Z-Stack," Application Note AN053(Rev. 1.0).

[32] "A True System on Chip solution for $2.4 \mathrm{GHz}$ IEEE 802.15.4 / ZigBee ${ }^{\circledR}$, , CC2430 Data Sheet (Rev. 2.1), May 2007.

[33] O. Landsiedel and K. Wehrle, "AEON: Accurate prediction of power consumption in sensor networks," in Proceedings of The Second IEEE Workshop on Embedded Networked Sensors (EmNetS-II), 2004.

[34] B. L. Titzer, "AVRORA: Scalable sensor network simulation with precise timing," in Proceeding of the 4TH International Conference on information processing in Sensor Networks (IPSN), 2005, pp. 477-482.

[35] B. University. How to measure State-of-Charge. [Online]. Available: http://batteryuniversity.com/learn/article/how_to_measure_state_of_char ge

[36] (2011) ATmega128/ATmega128L: 8-bit Atmel microcontroller with 128K-Bytes in-system programmable flash. [Online]. Available: http://www.atmel.com/Images/2467S.pdf

[37] "CC1000 Single Chip Very Low Power RF Transceiver," CC1000 Data Sheet.

[38] "System on Chip for $2.4 \mathrm{GHz}$ ZigBee ${ }^{\circledR}$ / IEEE 802.15.4 with Location Engine," CC2431 Data Sheet (Rev. 2.0.1), May 2007.

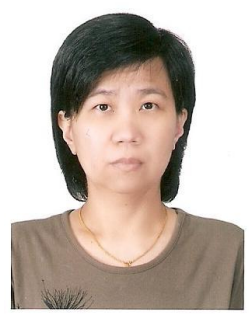

Wilawan Rukpakavong graduated BSc in Computer Science from Thammasat University, M.Sc. in Computer Science from Asian Institute of Technology, and MSc in Computer Network from the University of Derby. She has served as a Lecturer at Thammasat University, Thailand since 1991. Now she is a PhD student at the Department of Computer Science, Loughborough University. Her research interests include efficient energy and lifetime of wireless sensor networks.

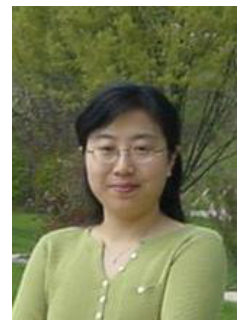

Lin Guan is a Senior Lecturer in the Department of Computer Science at Loughborough University. She received her PhD from the University of Bradford, UK, after which she was also appointed as a Research Associate. She then held a project manager/software engineer position in Simulation Systems Ltd shortly, prior to moving to Loughborough as a Lecturer in 2006. Her research interests focus on performance modelling/evaluation of heterogeneous computer networks, QoS analysis and enhancements, mobile computing and wireless sensor networks. She has published over 70 journal and conference papers and she has been serving as guest co-editor for several international journals, such as those published by Elsevier and Springer. During her $\mathrm{PhD}$, she was awarded the British Federation of Women Graduates Foundation Main Grant in 2004. She holds two CASE awards and one EngD on EPSRC/BAE funded projects. She recently received a prestigious award as Royal Society Industry Fellow and EPSRC KTA project.

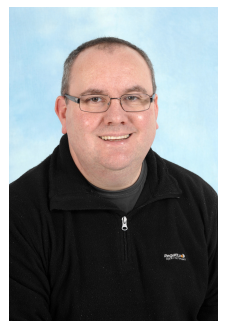

Iain Phillips has been involved in computing research for over 20 years, with over 100 publications in this area. His main work has been in network architectures considering performance and algorithms for the Internet and Wireless Sensor Networks.

$\mathrm{He}$ graduated from Manchester University with a BSc in Computing and Information Systems and a $\mathrm{PhD}$ in Computer Science - Thesis title Workload Distribution on Massively Parallel Machines. After 7 years post-doctoral research at Loughborough in the High Speed Networks group in Electrical Engineering (Research Assistant/Research Fellow), he moved to Loughborough Computer Science as a Lecturer in 1999, Senior Lecturer in 2005 and Head of Department 2008-11. From 2009-11 he was Vice Chair of the Council of Professors and Heads of Computing (CPHC) and from 2012-14 Chair. He is a Chartered Fellow of the BCS and a member of the ACM. 